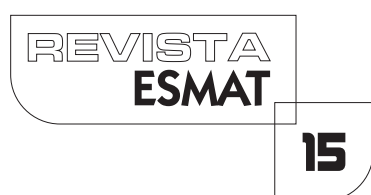

\title{
A NATUREZA HÍBRIDA DO INCIDENTE DE RESOLUÇÃO DE DEMANDAS REPETITIVAS A PARTIR DA NOVA SISTEMÁTICA PROCESSUAL
}

\author{
THE HYBRID STRUCTURE OF THE RECURRENT CASES INCIDENT FROM THE NEW \\ PROCEDURAL SYSTEMATIC
}

João Vitor Ferreira de Faria Negrão

Mestrando em Direito, da Universidade Nove de Julho - São Paulo -, com ênfase em Justiça, Empresa e Sustentabilidade. Pós-Graduado Lato Sensu em Direito Processual Civil, pela Universidade Anhanguera-Uniderp. Advogado.E-mail: jv.ffn.84@gmail.com

Mônica Bonetti Couto

Programa de Mestrado em Direito da Universidade Nove de Julho. Mestre e doutora pela Pontifícia Universidade Católica de São Paulo (PUC/SP). Especialista pela Universidade Federal do Paraná. Professora Permanente e Pesquisadora do Programa de Mestrado em Direito da Universidade Nove de Julho - São Paulo. Advogada e parecerista. E-mail: monicabonetticouto@yahoo.com.br

\section{RESUMO}

Este artigo tem como pretensão expor acerca da hibridez funcional do incidente de resolução de demandas repetitivas, instituto traduzido pelo novo Código de Processo Civil (Lei n 13.105, de 2015), posto bem servir à representação da nova sistemática processualista concebida pelo mencionado diploma. Elucidando a natureza híbrida ou dupla do incidente de demandas repetitivas é que levamos à compreensão de que o novo Código de Processo, bem como qualquer outro produto legislativo, não mais persiste à luz de uma atividade hermenêutica, consolidativa da norma jurídica, embasada em uma teoria superada do direito, havendo de ser gerido e dirigido sob alicerces humanistas, em congruência com núcleo essencial jurídico internacional. Para o desenvolvimento desta pesquisa, foram utilizados o método hipotético-dedutivo, histórico e pesquisas bibliográficas.

PALAVRAS-CHAVE: Novo Código de Processo Civil; Incidente de Resolução de Demandas Repetitivas; Natureza Híbrida; Precedentes Judiciais.

\section{ABSTRACT}

This article intends to expose the functional hybridity of the incident of recurrent cases 
resolution, an institute previewed by the new Code of Civil Procedure (Law 13. 105/20 I 5), that is a good exemple of the new process system conceived by the new code. Elucidating the hybrid structure of this incident is the best way that we have to the understand that new procedure by the code, also as any other legislative product, no longer persisting a law interpretation based on a old right's theory, must be managed and directed under humanistic foundations, in congruence with essential international legal codes. For the development of this research was used the hypothetical deductive method, historical and bibliographical research.

KEYWORDS: New Civil Procedure Code; Recurrent Cases Incident; Hybrid Structure. Precedents.

\section{INTRODUÇÃO}

Com o advento do novo Código de Processo Civil (Lei n 13.105, de 2015), em nosso ordenamento jurídico, muitos debates vêm surgindo acerca dos novos institutos ali previstos, atentando juristas e cientistas a enfrentarem o processo civil a partir de uma visão atual do direito.

Isso porque com o novo diploma, viu-se consolidar, em nosso sistema, uma nova fase metodológica do processo civil, a qual, afeiçoando-se à fase atual do direito, expressa uma nova maneira de enfrentar os problemas da sociedade pós-moderna, em particular, para o que nos interessa, os relacionados à crise do Judiciário.

Assim é que o presente trabalho tem a aspiração de colaborar com o estudo do novo diploma processual, alicerçado ao novo sistema de processo do novo Código de Processo, que, como dito, adaptando-se às necessidades da pós-modernidade e acompanhando a evolução do direito, Estado e sociedade, conduz à verdadeira face dos institutos que o integram.

Dessa maneira, o presente artigo começará com um brevíssimo histórico da evolução do liberalista até os tempos atuais, permitindo a compreensão do ambiente de surgimento da Constituição Federal, de 1988, sob a qual o Código de Processo Civil, de 2015 , é ordenado, disciplinado e interpretado.

No item seguinte, enfrentar-se-á o tema central deste trabalho, analisando-se a natureza híbrida ou dupla do incidente de demandas repetitivas, sob a compreensão de que o novo Código de Processo, bem como qualquer outro produto legislativo, não mais persiste à luz de uma atividade hermenêutica, consolidativa da norma jurídica, embasada numa teoria superada do direito, havendo de ser gerido e dirigido sob alicerces humanísticos e cooperativos.

O presente artigo adotará o método dedutivo-hipotético de abordagem, utilizando o procedimento dos métodos histórico, comparativo e sociológico, fazendo uso da interpretação sistemática. O tipo de pesquisa é o bibliográfico, a partir de livros e artigos científicos e, ainda, da pesquisa documental, pela análise da legislação. 


\section{BREVE HISTÓRICO EA CONSTITUIÇÃO FEDERAL, DE I 988}

Para os fins do presente ensaio, parte-se de um primeiro modelo de Estado e Direito constituído pela lei, surgido a partir da tentativa de libertação das amarras do absolutismo dos monarcas e senhores feudais, período que remete ao lluminismo, conhecido como Liberal.

A este primeiro modelo de estado constitucional, deu-se o nome de Estado Liberal Mínimo, onde as maiores preocupações das Constituições da época eram romper definitivamente com o modelo anterior, baseado na concentração total do poder nas mãos do monarca. (SILVA, 2016, p.213)

Dessa maneira, a onda liberal, posterior ao Estado absolutista, que pregava "o 'culto à norma', ao 'direito positivo', explicado pela 'dogmática'", preocupava-se, sobremaneira, "com sua vigência, e não com sua eficácia (ou validade)" (GOMES e MAZZUOLI, 20I0, p. 3 I), restringia o direito à lei, tão só e apenas. É dizer,

As constituições do período limitavam-se a regular a organização do estado, calcado na teoria tradicional da separação dos poderes, cada qual com sua esfera de atribuições bem definida e de garantir os direitos individuais dos cidadãos, como clara resposta ao modelo opressor que substituía (SILVA, 2016, p.213)

Depreende-se desse período:

O pensamento liberal tinha reservas quanto ao Estado, assim, a melhor forma de proteção dos direitos do homem seria a interferência mínima estatal. A compreensão abstrata da liberdade e da igualdade e a garantia da propriedade encerravam o principal objetivo do liberalismo, materializado nas declarações americana e francesa. (BENACCHIO e SANCHES, 20I2, p. 378)

O Direito não se encontra mais alicerçado aos dogmas do liberalismo, os quais - não obstante superados há décadas - ainda servem de base estrutural ao pensamento jurídico de muitos brasileiros.

liberalismo pôde ser constatado pela libertação da sociedade burguesa dos Estados absolutistas. A luta contra o totalitarismo deste modelo de Estado resultou no rompimento da monarquia, consolidando-se a tripartição dos poderes em um novo modelo de Estado. Repousado na lei como fonte única normativa e regulatória da 
organização estatal, o Estado Liberal positivou direitos individuais, calcado no ideal de liberdade. O papel do juiz era apenas de declaração da vontade da lei (do legislador); com severa restrição hermenêutica, a burguesia procurava evitar, dessa forma, os notórios excessos praticados pelos julgadores da era absolutista. Nesse sentido:

No limite, portanto, a dogmática almeja tornar possível a redução da experiência jurídica à dimensão estrita da norma. Para tanto, configura o jurídico como uma realidade que se basta a si mesma, ou seja, que é capaz de se autofundar e de não ser condicionada nem por poderes coercitivos absolutos nem por ideologias. A dogmática concebe o direito - enquanto força legal destinada a impedir ou neutralizar o uso privado da violência - como uma técnica de produção de mandatos mediante procedimentos disciplinados pelo próprio direito. Nesta perspectiva, é o direito que regula sua própria criação; é o direito que gera e molda o próprio direito, enfim, é o direito que se autoproduz. E ao vê-lo assim não como fato social ou como valor transcendental, porém apenas como um conjunto de regras positivas sob a forma de uma ordem coativa, ela também permite a conversão do pensamento jurídico num aparato conceitual depurado de contaminações valorativas. Deste modo, o pensamento jurídico não está autorizado a promover julgamentos morais ou avaliações políticas sobre a experiência jurídica, devendo encarar as relações sociais concretas exclusivamente pela ótica das prescrições normativas, ou seja, pela relação de imputação entre sanções e atos considerados ilícitos. (FARIA, 2002, p. 45)

Entretanto, o apego à formalidade e a distância imposta ao direito ante os demais ramos da ciência, que apostavam somente na lei como definidora de uma suposta sociedade livre e organizada, culminaram em episódios de extremos atentados à própria espécie humana, catástrofes artificiais que obrigaram a uma redefinição do direito, passando-se a dar a devida atenção ao que hodiernamente se concebe como direitos humanos.

A esse respeito registra-se, com precisão, na doutrina:

A história vivenciou, a partir do século XVIII, com a queda do estado absolutista e a propagação das ideias iluministas, o nascimento do estado constitucional, onde o poder na mão do governante deixa de ser absoluto e passa a ser limitado/regulado por uma lei maior, que também passa a garantir diversos direitos das pessoas perante os abusos até então cometidos pelo estado. (SILVA, 20 | 6, p.2।3). 
O legalismo, puro e extremo, favoreceu a existência de diversos governos autoritários e ditatoriais. De fato, a chamada "crise de legalidade" veio a revelar que a subordinação dos Poderes Públicos unicamente à lei "nunca foi um artifício inteiramente eficaz para a contenção das formas absolutistas ou autoritárias de exercício do poder. Ou seja, no Estado de Direito Liberal (que é um Estado da legalidade), o poder continua sendo exercido sem os devidos limites ou sob limites puramente formais (o que significa atuar sem controle bem definidos)." (GOMES e MAZZUOLI, 20 I 0, p. 37)

Por isso, a primeira metade do século $X X$, significativamente a partir das aversivas guerras mundiais, marca a passagem de um novo período histórico, concebendo-se o direito a partir de nova perspectiva.

Num corte metodológico aleatório e não muito distante na história, pode-se citar como eventos ou circunstâncias sociais e politicas relevantes, que moldaram o mundo, nos fazendo chegar até onde hoje nos encontramos, as revoluções liberais do epílogo do século XVIII delimitando a idade moderna, com os ideais iluministas em efervescência, a revolução francesa, a revolução industrial, o início da urbanização, a consolidação dos métodos de produção e consumo de massa, a luta capital e trabalho, as duas grandes guerras mundiais, o longo período da guerra fria, com a derradeira queda do muro de Berlim e a derrocada do socialismo, assim como a globalização. (MEDEIROS NETO e MACHADO, 20 I 6, p. I68)

Surge, assim, o constitucionalismo e seus desdobramentos evolutivos quase simultâneos, partindo-se das premissas de que "a subordinação da lei à Constituição não pode ser compreendida como mera 'continuação' dos princípios do Estado legislativo, pois significa uma transformação que afeta as próprias concepções de direito e jurisdição" (MARINONI, 20I I, p.68), sendo o direito compreendido a partir dos direitos humanos fundamentais,

logo após a Segunda Guerra nasceram (congênitos) três movimentos: o constitucionalista, o internacionalista e (ainda que de forma incipiente nesse primeiro momento, mas com nítidas evoluções futuras) o universalista. $\bigcirc$ Estado de Direito constitucional é regido (sobretudo) pela Constituição de cada país: esse modelo de Estado de Direito é criado e aplicado pelos legisladores e juízes internos respectivos. $\bigcirc$ Estado de Direito Internacional possui outra estruturação: ele é fruto da vontade de muitos Estados (que aprovam convenções e tratados internacionais) de forma coordenada, e no exercício de suas atribuições independentes. Mas não são dois modelos excludentes; ao contrário, são complementares um ao outro. [...] Cada uma delas corresponde a uma onda evolutiva que vai do Estado absolutista ao Estado constitucional e humanista de 
direito. (GOMES e MAZZUOLI, 20 I 0, p. 77/78)

Os ideais dessa nova onda evolutiva pelo mundo convergiram nos assim denominados direitos humanos fundamentais, ou seja, o foco nos direitos humanos passa a ser o ponto comum entre os Estados democráticos.

A passagem do constitucionalismo ao período internacionalista é sutil, pois são quase concomitantes. A atenção primordial aos direitos humanos propiciou a criação dos organismos internacionais e a concordância dos países aos pactos e tratamentos desses direitos fundamentais. No Brasil foi positivado: somos signatários dos principiais documentos normativos externos a respeito dos direitos humanos fundamentais.

Com o desenvolvimento da ideia de dignidade humana no âmbito da filosofia, ela passa a se tornar, ao longo do século XX, um objetivo político. A Constituição da República Federativa do Brasil, promulgada em 1988, faz menção explícita - de maneira inédita na história constitucional brasileira - ao princípio da dignidade da pessoa humana logo em seu primeiro artigo, onde elenca os fundamentos da República. (COELHO e MELLO, 201।, p. 16)

Essa nova roupagem do direito, alicerçado em bases humanísticas, sem isolamento do direito com a moral e demais campos da ciência, e a constitucionalização do princípio dos direitos humanos "modifica, em sua raiz, toda a construção jurídica; ele impregna toda a elaboração do Direito, porque ele é o elemento fundante da ordem constitucionalizada e posta na base do sistema." (COELHO e MELLO, 20 I I , p. 17).

De fato, a Constituição brasileira, de 1988, foi promulgada seguindo essa nova roupagem conceptiva do direito, sendo, aliás, diploma representativo internacionalmente acerca dos direitos fundamentais.

As primeiras constituições constitutivas são a mexicana de 1917 , que passa prever em seu bojo princípios aplicáveis ao trabalho, que até então eram regulados pela livre iniciativa entre empregador e empregado, além de prever regras de previdência social; e a Constituição de Weimar de 1919 e que regeu o estado alemão até 1933, que passou a dar ênfase aos direitos sociais e econômicos, definiu a economia como uma questão do estado alemão (lembrando-se que até então a economia era baseada na autorregulação do mercado, sem qualquer interferência estatal), sendo importante reproduzir o artigo | 5 | deste diploma legal que dizia: 'A organização da vida econômica deverá realizar os princípios da justiça, tendo em vista assegurar a todos uma existência conforme à dignidade humana' $[\ldots]$ É dentro deste conceito de estado social e interventor, e constituição dirigente que é promulgada em 1988 a nossa Constituição Federal. (SILVA, 20 I 6, p. 214/2। 5) 
A Constituição Federal, de 1988, acompanhou a evolução da sociedade, Estado e direito, brotando em ambiente que se desgarrava dos paradigmas individualistas, tendo concepção coletiva desenvolvimentista social, ou seja, acompanhando "a necessidade de mudança do paradigma individualista para o coletivo-colaboracionista." (ANDREUCCl, 20।3, p. 230).

Isso porque sabemos que o liberalismo tornou-se um sistema inoperante diante do fenômeno da revolução das massas. Em face da transformação sociopolítica-econômica-tecnológica, percebeu-se a necessidade de um modelo estatal intervencionista, com a finalidade de reequilibrar o mercado econômico. Com isso, a noção e o conceito de desenvolvimento, formados num Estado de concepção liberal, alteraram-se, porquanto não mais encontravam guarida na sociedade moderna. (FIORILLO, 20 I3).

O Código de Processo anterior, de 1973, conquanto recepcionado pela Constituição Federal, de 1988, mas não se adequou à nova realidade, tornando necessárias incontáveis alterações legislativas nesse sentido, até mesmo emendas na própria Constituição (revelando-se de enorme relevância substancial a Emenda Constitucional $n^{\circ} 45$, de 2004). Mas, ainda assim, a solução - ou ao menos a amenização - dos problemas advindos da quantidade avassaladora de processos submetidos ao Judiciário, as lacunas legislativas, e a diversidade de decisões acerca de casos semelhantes, parecia inatingível, ante a resistência cultural brasileira do "apego à lei" e a dificuldade natural do ser humano diante da mudança, apesar da nobreza da Constituição da República em vigor e sua coerência com a teoria atual do direito.

Essa mudança, apesar de parecer difícil, revela-se imperativa, até porque, no "Estado constitucional, as normas constitucionais e os direitos fundamentais dão unidade e harmonia ao sistema e, por isto, obrigam o intérprete a colocar o texto da lei na sua perspectiva." Isto é, "as normas constitucionais são vinculantes da interpretação das leis" (MARINONI, 20II). Ora, o processo, garantia dos jurisdicionados à completude da norma, pacificador social e determinador da previsibilidade comportamental, tem seu alicerce "na Constituição, sendo codependente dos direitos fundamentais. Assim, o que sustenta a noção de processo como garantia são os princípios constitucionais do processo definidos no texto constitucional." (BARROS, 20।3, p. 49).

processo civil vive uma crise de efetividade decorrente do formato adotado na codificação de 1973, que, conquanto as várias reformas que sofreu, não mais atendeu às necessidades de uma sociedade massificada, potencializada com o desenvolvimento tecnológico das telecomunicações e o advento da internet, impondo uma velocidade no acesso a informações nunca antes vista. Vivemos em um mundo em 
tempo real, conectados, com rápido e abrangente acesso ao que ocorre no nosso globo. (MEDEIROS NETO e MACHADO, 2016, p. 165)

Nesse ambiente, revelou-se a relevância do advento do novo Código de Processo Civil, tornando inelutável a quebra do paradigma estabelecido, uma vez que aparenta, no mínimo, "haver um consenso no sentido de que o processo judicial clássico não é o bastante para resolver controvérsias carregadas de matizes sociais que afetam a grupos, categorias ou classes de cidadãos." (SIMÃO, 2015, p. 2).

O diploma em análise apresenta nova sistemática processual, que somente pode ser devidamente compreendida pelo estudo fundamentado nesta percepção que se pode dizer contemporânea do direito.

O estabelecimento definitivo do ser humano como destinatário da norma jurídica, que coloca o juiz como "super-parte" de atuação preponderante no processo jurisdicional (BARROS, 2013, p. 47), coincide com a fase atual em que encontra a sociedade, Estado e Direito caminho a ser galgado no sentido da solução ou amenização dos principais problemas ligados ao Poder Judiciário.

Desse modo, tomando como marco o paradigma procedimentalista do Estado Democrático de Direito, visto pela teoria do discurso de Habermas (1997) na perspectiva do sujeito de direito que se coloca como sujeito e destinatário da norma jurídica, é possível estabelecer uma crítica à teoria do processo como relação jurídica, justamente em razão do lugar do juiz como "super-parte", e ao instrumentalismo, em virtude do solipsismo do juiz e dos escopos metajurídicos do processo jurisdicional.

Ao mesmo tempo, pode-se pretender a apropriação da teoria do processo como procedimento em contraditório, como adequada ao paradigma do Estado Democrático de Direito, principalmente em razão da compreensão do processo para além da jurisdição, já que o processo, no paradigma procedimentalista, deve ser entendido como constitutivo de direitos fundamentais. Ademais, a noção de contraditório pretendida pela referida teoria do processo consolida a proposta de garantia de participação em simétrica paridade dos afetados pelo provimento, no sentido de uma garantia de construção participada da decisão, que estarão compreendidos no processo tanto como autores, quanto como destinatários da norma jurídica. (BARROS, 20।3, p. 48).

O sistema de processo hoje positivado pelo novel diploma processual exige do operador do direito honroso exercício de reestruturação teórica com desprendimento das concepções antiquadas, então calcadas em realidade não mais existente. $\bigcirc$ mundo 
globalizado e tecnológico, com trânsito e acesso rápido e fácil da informação, aliado a toda a trajetória histórica acima descrita impõem aos juristas e cientistas adequação do processo judicial às ambições do novo código processualista, as quais se encontram alinhadas ao atual momento evolutivo da sociedade, Estado e Direito.

Neste contexto, a ideia de absoluta, ou de preponderante neutralidade, tem que ser abandonada, e o Juiz passa a se politizar, a ter que gerenciar com mais eficácia a sua atuação, a preocupar-se com o aspecto finalístico da atividade judicante, com as consequências das decisões judiciais, visando dar respostas que atendam a essa sociedade massificada, eminentemente consumista. (MEDEIROS NETO e MACHADO, 2016, p. 17I).

novo Código desponta na tentativa de acompanhar as mudanças internas e internacionais, não apenas absorvendo institutos pontuais de outros países, mas criando um verdadeiro novo sistema processual com base nessa nova teoria do direito, abandonando a sistemática do Código de Processo Civil, de 1973, e a ultrapassada teoria da relação jurídica.

Parte-se para novos rumos, atentando para um processo de operação conjunta, isto é, de cooperação entre todas as partes integrantes, impondo um diálogo processual entre juiz, demais participantes do processo e a própria sociedade, haja vista que "essa postura cooperativa no âmbito do processo civil está justamente ligada à concretização da liberdade e da igualdade e do compromisso de todos com a solução pacífica e justa dos conflitos." (MEDEIROS NETO e MACHADO, 20 I6, p. 177).

Impõe-se abrir uma parênteses para estancar as descabidas alegações de existência de algum tipo de "commonlização" do direito brasileiro, a necessidade de previsão expressa para vinculação de precedentes judiciais é a maior expressão da natureza civil law do nosso ordenamento jurídico - mesmo que já superada a concepção de tradicional dicotomia na divisão entre as famílias do direito -, já que na common law tal imposição é de todo desnecessária, por substância do próprio significado e surgimento do instituto naquele sistema jurídico.

Ora,

O retorno à realidade fática evidenciada num precedente judicial e debatida publicamente pelas coletividades no processo decisório é fundamental para a eficácia dos direitos e garantias afetadas aos movimentos sociais, o que contribui para a superação de uma cultura jurídica individualizante. Nesse escopo de análise, a participação dos movimentos sociais nas ações constitucionais constituem importantes dados empíricos que apontam para a ampliação das disputas sociais no campo jurídico e o fortalecimento da democratização das decisões judiciais. (CATHARINA, 20 I6, p. 37). 
Já que a partir do momento em que a "lei e sua visão codificada perdeu sua posição central como fonte do direito e passou a ser subordinada à Constituição, não valendo, por si só, mas somente se conformada com a Constituição e, especialmente, se adequada aos direitos fundamentais e aos direitos humanos" (LEÃO JÚNIOR e SACONATO, 2015, p. 219), tornou-se imprescindível o envolvimento mais direto e ativo da sociedade nas causas submetidas ao Judiciário, para condução do grau de relevância e efeitos além do processo e partes, que alcança e interessa à coletividade.

Insta alertar que a assertiva supra não importa na afirmação de que common law seja o mesmo que precedente ou que ambos possam ser confundidos ou até mesmo que nasceram juntos, pois o stare decisis e a vinculação dos precedentes são posteriores ao despontamento do sistema consuetudinário da common law, fonte normativa nos costumes; não se confunda, assim, fonte com sistema de precedente. No Brasil, a fonte tradicionalmente reside na lei, e o sistema processual encontrava-se instituído na teoria da relação jurídica processual.

Já na nova sistemática em nosso País, a qual abarca um sistema de precedentes, contemplam-se institutos que visam servir ao sistema processual instaurado, uma vez que na esteira da contemporaneidade da sociedade, Estado e Direito, como é o caso do incidente de resolução de demandas repetitivas, são constantes do novel Código de Processo Civil. Atualmente, o sistema se institui na teoria do processo constitucional, cooperativo democrático, humanista.

A seguir, volta-se ao tratamento da dupla função ou natureza desse instituto, como forma de colaborar para as linhas introdutórias de um futuro aprofundamento do incidente de resolução de demandas repetitivas à luz da contemporaneidade do direito, mas consideradas premissas básicas e elementares à sua devida compreensão.

\section{COMPREENDENDO A NATUREZA HÍBRIDA DO INCIDENTE DE RESOLUÇÃO DE DEMANDAS REPETITIVAS}

O incidente de resolução de demandas repetitivas, considerado "uma das grandes apostas do CPC/20 I 5 no tratamento das chamadas causas seriais" (BAHIA, 20I5, p. 1 526), encontra-se previsto nos artigos 927,928 e 976 a 987 da referida Carta.

Especializada doutrina vem apontando duas inspirações desse incidente, estando uma descrita na Exposição de Motivos do novo código processualista: o modelo chamado de processo-modelo alemão. A outra influência tem sido atribuída ao modelo chamado de processo-piloto de outros países, como a Áustria.

No que se refere ao "sistema da causa-piloto, o órgão jurisdicional seleciona um caso para julgar, fixando a tese a ser seguida nos demais. Já na causa-modelo, instaura-se um incidente apenas para fixar a tese a ser seguida, não havendo escolha de uma causa a ser julgada" (DIDIER JR., 2017, p. 677). Nessa esteira, enquanto em um modelo somente se julga a tese para ser aplicada aos processos semelhantes, no outro se julga também o caso constante do processo-piloto. 
Ainda que, pelo acima explanado, se pudesse sugerir que o modelo adotado pelo Brasil foi o do processo-piloto (e, portanto, o modelo austríaco), a Exposição de Motivos do novo Código deixa evidente a sua inspiração no modelo alemão.

Importante dispositivo do novo código eleva a discussão, quando expressamente determina que a desistência ou o abandono do processo não impede o exame de mérito do incidente.

$\bigcirc$ questionamento que emerge intuitivo é o da possibilidade de o mérito ser analisado quando o autor desiste ou abandona o processo (já que o processo deveria ser extinto sem julgamento do mérito, não havendo resolução do caso pela jurisdição). Essa linha de pensamento encontra guarida na lógica da relação jurídica processual (então vigente no antigo diploma processual), mas óbice para a compreensão da previsão legal expressa do $\S 1^{\circ}$ do artigo 976. Isto é, à luz da teoria da relação jurídica, sem o autor (que desistiu do processo) a relação jurídica processual não se encontra perfeitamente formada, não se cogitando julgar o mérito de uma demanda em que o autor não se encontra ali afirmando seu direito.

Como amplamente exposto linhas acima, a sistemática processual agora é outra. $\bigcirc$ novo Código de Processo Civil encerra o sistema processual que vigorava sob a égide do diploma passado, que não mais encontra compatibilidade com um modelo de processo humanista e cooperativo.

novel diploma em estudo se coaduna com uma processualística que atende ao Estado humanístico de Direito, sedimentado nos direitos humanos fundamentais internacionalmente reconhecidos, atendendo à necessidade de ampliação da participação democrática dos jurisdicionados no processo, que a teoria da relação jurídica não proporcionava e deixava o juiz em superioridade ante as demais partes do processo.

\begin{abstract}
Aliás cabe realçar que logo em seu primeiro artigo o novo CPC proclama reveladora mensagem, qual seja, a de que o processo civil será ordenado, disciplinado e interpretado conforme os valores e as normas fundamentais estabelecidos na Constituição da República Federativa do Brasil.

Ou seja, não diz que será orientado pela Constituição tão somente, mas sim pelos valores e normas fundamentais que dela se extraem, o que é significativo no sentido de se compreender o caráter de busca de um formato de processo que esteja comprometido substancialmente com a busca da justiça, ou por outro enfoque, da resposta jurisdicional que detenha $\mathrm{o}$ atributo da efetividade, sob os auspícios de um formato de processo dialogal, que melhor se harmoniza com o devido processo legal, num Estado Democrático de Direito. (MEDEIROS NETO e MACHADO, 2016, p. I78).
\end{abstract}

A base solidária e humanista da nova teoria do direito alcançou o direito processual e 
infundiu a imprescindibilidade de um processo que atendesse substancialmente a este (novo) panorama, que somente é possível por meio de uma sistemática verdadeiramente constitucional e cooperativa, obrigando todas as partes do processo na mesma medida.

É nesse ambiente desafiador que se gestou o novo CPC, que traz dentre as suas inovações um modelo de processo cooperativo, a superar os modelos tradicionalmente conhecidos (inquisitorial e dispositivo), pois passa a exigir-se a participação efetiva de todos os atores processuais e até mesmo da sociedade, na construção de processos équos e justos, nos quais, numa perspectiva de democracia participativa, o método da codificação foi o de comprometer juiz e partes a manter permanente o diálogo, num relacionamento simétrico, na fase instrutória do processo. (MEDEIROS NETO e MACHADO, 2016, p. 165).

Essas são premissas fundamentais no intuito de verificar as funções do incidente de resolução de demandas repetitivas e a questão da sua influência.

Sua inspiração é o processo-modelo das controvérsias do mercado de capital alemão.[...] Este é o grande objetivo do Incidente, afinal, suspender a tramitação das causas em que a questão repetitiva esteja presente para que esta seja resolvida e, após, os processos voltem ao seu trâmite normal tendo já solucionado aquele debate. $\bigcirc$ que o IRDR faz é uma cisão da cognição através de técnica conhecida como 'procedimentomodelo' - não se trata de uma ação autônoma, mas de um tipo especial de incidente processual. (BAHIA, 20 I 5, p. I526).

Seguem então muitos entendimentos de que o novo código adota o processomodelo, até mesmo por ocasião da possibilidade de a desistência ou abandono do processo não evitar o julgamento do mérito, sendo que, para alguns, "o sistema de resolução de demandas repetitivas não visa diretamente conceder a prestação jurisdicional ao cidadão" (SIMÃO, 20 I 5, p. I3).

A esse propósito, importa colacionar as lições de TEMER, para quem:

A definição da natureza do incidente é tarefa complexa, porque a lei não é clara a respeito de um aspecto essencial para determiná-la: saber se o incidente compreenderá julgamento da 'causa', ou seja, do conflito subjetivo que levou à sua instauração, ou se apenas haverá resolução pontual da questão de direito, em abstrato, fixando-se a tese jurídica sem a resolução de conflitos subjetivos [...] Adotamos a posição 
segundo a qual $\mathrm{o}$ incidente de resolução de demandas repetitivas apenas resolve a questão de direito, fixando a tese jurídica, que será posteriormente aplicada tanto nos casos que serviram como substrato para a formação do incidente, como nos demais casos pendentes e futuros. Entendemos, portanto, que no incidente não haverá julgamento de 'causa-piloto', mas que será formado um 'procedimento-modelo'. (TEMER, 2016, p. 65/66 e 69).

Contudo, desafia esta tese a constatação de que o julgamento do mérito com desistência ou abandono do autor constitui exceção, não apenas por cuidar de situações não preponderantes na prática, como também pela interpretação sistêmica que se realiza do dispositivo - não fosse exceção, não estaria localizado no $\S I^{\circ}$. A regra, dessa maneira, é o julgamento da tese e também do processo na qual se insere, e que foi selecionado para representar os demais processos em que se discute a mesma tese.

$\bigcirc \S 1{ }^{\circ}$ mostra que o IRDR não se dá apenas em função de um interesse particular, mas de um interesse público na estabilização de entendimento quanto a determinada questão repetitiva, por isso a desistência/abandono por seu autor não impede que o Tribunal o julgue no mérito, devendo, em tais casos, o procedimento ser assumido pelo Ministério Público $(\S$ $2^{\circ}$ ). Pelas mesmas razões o $\S 3^{\circ}$ estabelece que a inadmissão em uma primeira tentativa de instaurar o Incidente não impede que ele seja intentado novamente. (BAHIA, 20I5, p. 1527).

O processo-piloto é que apresenta modelo em que a causa é julgada, não somente a tese, o que levanta a questão de sua adoção, podendo levar à posição de que o novo Código teria preferido o modelo processo-piloto, uma vez que, como o "tribunal, no IRDR, julga a causa e fixa o entendimento a ser aplicável aos demais casos repetitivos", teríamos "uma causa-piloto, e não uma causa-modelo" (DIDIER JR., 20 I7, p. 678), aludindo ainda ao Enunciado 344 do Fórum Permanente de Processualistas Civis.

Parece-nos acertada, a esse respeito, a posição de Fredie Didier Jr., para quem se afigura a existência de um modelo, por assim dizer, "misto", tendo em vista a exceção do $\S 1^{\circ}$ do artigo 976 do Código de Processo, e ainda a dupla função atribuída ao incidente de resolução de demandas repetitivas.

Embora o sistema brasileiro de julgamento de casos repetitivos seja de causa-piloto, é preciso observar a hipótese de haver desistência da demanda ou do recurso voluntário afetado para julgamento [...] Nesses casos, ocorre uma exceção á regra geral, caracterizando-se uma hipótese de causa-modelo. [...] Quando se seleciona um caso para julgamento, instaura-se um novo procedimento. Esse procedimento incidental é instaurado 
e não se confunde com o processo principal originário ou recursal. [...] Tal desistência, todavia, não atinge o segundo procedimento, instaurado para definição da tese a ser adotada pelo tribunal. [...] Abstraída essa hipótese, o que se tem é uma causa-piloto, com julgamento do caso. (2017, p. 679/680)

Entre os estudiosos, parece não haver dúvida de que o Incidente de Resolução de Demandas Repetitivas se presta tanto a resolver os casos que estão em andamento discutindo tese idêntica, como "o grande objetivo do IRDR é a uniformização e a geração de segurança jurídica sobre questão repetitiva controversa” (BAHIA, 20 I 5, p. 1527).

O que se percebe é que o sistema de resolução de demandas repetitivas inaugurados pelo instituto da súmula vinculante e pelo sistema de julgamento de recursos repetitivos pelo Supremo Tribunal Federal e pelo Superior Tribunal de Justiça visa, primordialmente, a fixação de teses jurídicas e, com isso, procura-se conferir maior racionalidade e celeridade à prestação jurisdicional. A rigor, a lógica da resolução dos conflitos coletivos pela súmula vinculante e pelo julgamento de recursos repetitivos é tornar o sistema mais eficiente. (SIMÃO, 2015, p. 12).

"No Brasil, em linhas gerais, a Doutrina vem apontando que o objetivo do Incidente de Resolução de Demandas Repetitivas é (i) agilizar a prestação jurisdicional, (ii) diminuir o número de processos judiciais e (iii) gerar uniformidade na jurisprudência" (SIMÃO, 20 I 5, p. 16), o que representa uma dupla funcionalidade do instituto.

Ante essas considerações, pode-se, desde já, apontar que o incidente em análise (inspirado no direito alemão) será admitido quando for possível identificar demandas com potencial multiplicador, as quais deverão ser analisadas em conjunto para impedir a existência de decisões conflitantes, bem como para otimizar o trabalho do Poder Judiciário, que poderá dedicar-se à análise de outras questões. (GOMES, 20 16, p. 27).

Ora, trata-se de "medida que igualmente converge no sentido de conferir isonomia e celeridade na prestação jurisdicional já que pretende adotar igual solução às relações jurídicas idênticas, respeitando um prazo adequado para a prestação jurisdicional." (AQUINO, 2016, p. 260).

Se é possível fundamentar o acolhimento do modelo alemão pelo Brasil pelas Exposições de Motivos do novel codex, mais árduo o trabalho de negar a hibridez do incidente de resolução de demandas repetitivas, já que à seu respeito suscita a referida exposição: 
Por enquanto, é oportuno ressaltar que levam a um processo mais célere as medidas cujo objetivo seja o julgamento conjunto de demandas que gravitam em torno da mesma questão de direito, por dois ângulos: a) o relativo àqueles processos, em si mesmos considerados, que, serão decididos conjuntamente; b) no que concerne à atenuação do excesso de carga de trabalho do Poder Judiciário - já que o tempo usado para decidir aqueles processos poderá ser mais eficazmente aproveitado em todos os outros, em cujo trâmite serão evidentemente menores os ditos "tempos mortos" (= períodos em que nada acontece no processo). Por outro lado, haver, indefinidamente, posicionamentos diferentes e incompatíveis, nos Tribunais, a respeito da mesma norma jurídica leva a que jurisdicionados que estejam em situações idênticas tenham de submeter-se a regras de conduta diferentes, ditadas por decisões judiciais emanadas de tribunais diversos. Esse fenômeno fragmenta o sistema, gera intranquilidade e, por vezes, verdadeira perplexidade na sociedade. [...] Essa é a função e a razão de ser dos tribunais superiores: proferir decisões que moldem o ordenamento jurídico, objetivamente considerado. A função paradigmática que devem desempenhar é inerente ao sistema. [...] Está-se, aqui, diante de poderoso instrumento, agora tornado ainda mais eficiente, cuja finalidade é a de uniformizar a jurisprudência dos Tribunais superiores, interna corporis. Sem que a jurisprudência desses Tribunais esteja internamente uniformizada, é posto abaixo o edifício cuja base é o respeito aos precedentes dos Tribunais superiores." (disponível em: https://www2.senado.leg.br/bdsf/bitstream/handle/id/5 I 2422 /00 I 04 I 135.pdf?sequence = I).

Denota-se do artigo 928 haver o gênero julgamento de casos repetitivos, de onde são espécies o incidente de resolução de demandas repetitivas e os recursos especial e extraordinário repetitivos. A espécie incidente de resolução de demandas repetitivas, objeto do presente artigo, apresenta duas funções, de forma a evidenciar a existência de dois microssistemas normativos: um voltado a gerir e julgar os casos pendentes; outro destinado à formação de precedentes judiciais. Juntos, servem aos princípios primordiais do processo constitucional cooperativo, estabelecidos na sistemática do novo código processualista civil.

"O Incidente de Resolução de Demandas Repetitivas deve servir como instrumento apto à pacificação social mediante a pacificação da jurisprudência a respeito da interpretação de determinada tese jurídica. Essa pacificação social deve se dar pela resolução das lides já em tramitação mas, ao mesmo tempo, pela orientação da sociedade e do Poder Público a respeito da tese jurídica fixada de forma a que os padrões 
comportamentais e sociais se adequem à tese jurídica fixada." (SIMÃO, 20I5, p. 32).

E não haveria de ser diferente, senão imagine-se a hipótese de um incidente "para tratar da possibilidade de retenção pelo promissário-vendedor dos valores pagos pelo compromissário-comprador de unidade imobiliário em condomínio edilício"; a tese jurídica será definida pelo Tribunal para resolver os processos em curso tratando dessa matéria. "Todavia, de nada adiantaria para a resolução das lides futuras se não houvesse aplicabilidade da tese jurídica fixada para os processos futuros." (SIMÃO, 20 I 5, p. 33).

Cuida-se de regramentos normativos com desígnios distintos, não se confundindo a técnica de administração para julgar os casos repetitivos, livrando o Judiciário de diversos casos pendentes sobre a mesma matéria, com a técnica para criação de precedentes obrigatórios, necessária à estabilização do sistema, segurança e previsibilidade, à igualdade.

Por isso, os procedimentos de cada microssistema também não se confundem, sendo-lhes próprios para servirem a seus respectivos fins. Desse modo, tem-se a técnica de escolha de um caso que contenha tese representativa da controvérsia para ser julgado, servindo de modelo para os processos pendentes com questão semelhante, os quais incorporarão a tese em suas respectivas decisões. Já a técnica para a formação de precedentes encontra-se determinada por sistema próprio.

O objetivo do IRDR e dos recursos repetitivos é conferir tratamento prioritário, adequado e racional às questões repetitivas. Tais instrumentos destinam-se, em outras palavras, a gerir e decidir os casos repetitivos. [...] também se destinam a formar precedentes obrigatórios, que vinculam o próprio tribunal, seus órgãos e os juízos a ele subordinados. [...] compõe, por isso, dois microssistemas, cada um deles relacionados a uma de suas duas funções. [...] Quer isso dizer que o julgamento de casos repetitivos é gênero de incidentes que possuem natureza híbrida [...] Esses microssistemas são compostos pelas normas do CPC e, igualmente, pelas normas da Consolidação das Leis do Trabalho - CLT que foram inseridas pela Lei n. 13.105/2014, a respeito de julgamentos repetitivos. (DIDERJR., 2017, p. 673/674)

A despeito do debate quanto ao modelo de julgamento do incidente adotado, sua hibridez desponta reluzente. Retornando à exceção, esta também se alinha, porque o direito de abandonar ou desistir do processo, seguindo o mérito para julgamento, demonstra o interesse público de fixação da tese acerca da questão, pois relevante ao sistema jurídico e ao Estado a administração dos processos repetitivos, julgando-os, e também a segurança pela formação do precedente para os casos futuros com questão idêntica. 
No caso hipotético de uma desistência, em que o mérito é julgado fixando-se tese favorável ao autor desistente, este não terá a efetivação de seu direito naquele processo, porque o resultado do incidente foi a fixação da tese a ser seguida em todos os processos pendentes. Uma vez que o autor desistiu, seu processo será extinto sem julgamento do mérito. Para os casos pendentes, haverá julgamento de acordo com a tese fixada, pois esta, estabelecida pelo Tribunal, irá integrar a fundamentação das sentenças respectivas, servindo ao procedimento do microssistema de gerência de casos repetitivos. A tese também servirá para a resolução de casos semelhantes futuros, cumprindo com a função de formação de precedentes obrigatórios - até mesmo beneficiando o próprio desistente, caso ingresse com novo processo, já que a tese fixada que lhe é favorável é, agora, vinculante. Com efeito:

A percepção de que há um microssistema, com natureza híbrida, é importante. Os instrumentos que formam o microssistema de gestão de julgamentos de casos repetitivos são regidos por normas comuns, que se intercomunicam, garantindo, assim, unidade e coerência. Para a gestão dos casos repetitivos e a formação de precedentes obrigatório, devem ser aplicadas as normas que compõe esses microssistemas, como normas que se complementam e se interpretam conjuntamente. (DIDERJR., 2017, p. 676)

Somente a compreensão da nova visão do direito, afastando as dicotomias teóricas tradicionais que não mais se coadunam com a realidade, que foi alterada diante das evoluções da sociedade, pode criar o campo intelectual fértil a conceber que o novo Código de Processo Civil positivou um sistema de precedentes obrigatórios, e tal não se incompatibiliza com o ordenamento jurídico brasileiro; o stare decisis pode se harmonizar com o sistema de cultura civil law.

O enfrentamento da crise do processo passa pela inovação não só de técnicas procedimentais positivadas em lei, mas também pela mudança da cultura e da postura dos atores do processo, que precisa ser remodelado para atender ao que dele se espera numa sociedade massificada pós-moderna. (MEDEIROS NETO e MACHADO, 20 I6, p. 165).

Indubitável a importância teórica e prática do incidente de resolução de demandas repetitivas. O presente estudo pretende colaborar na introdução ao tema, corroborando na ampliação de campos para discussão do instituto.

\section{CONCLUSÃO}

Analisou-se neste trabalho a natureza híbrida do incidente de resolução de demandas repetitivas com o fim de colaborar com o aprofundamento do estudo sobre o tema, haja vista a extrema relevância desse novo instituto ao atual sistema processual trazido pelo novo Código de Processo Civil. 
Para a compreensão dessa dupla funcionalidade, imprescindível a compreensão de uma teoria contemporânea do direito, até porque o mencionado jovem diploma encontra-se nesta fundamentado.

As influências externas do instituto e as celeumas a respeito conduzem à afirmação da hibridez do incidente de resolução de demandas repetitivas, muito também pela disposição do $\S I^{\circ}$ do artigo 976 do novel codex, pois escancara a superação da teoria da relação jurídica em que o antigo código era baseado, na linha da realidade, à época.

Diante de uma nova realidade e sociedade, Estado e Direito avançaram, o que conduz a ciência a um proceder repousado nos direitos humanos fundamentais, sobrepujando antigos dogmas.

A hipótese, portanto, funda-se no entendimento da natureza híbrida do incidente de resolução de demandas repetitivas, que se constitui a partir da nova sistemática processual do novo Código de Processo Civil. A compreensão da configuração funcional dúplice deste instituto está vinculada ao estado atual da sociedade, Estado e Direito.

Em outras palavras, não se compreende a natureza de um instituto hodierno sob paradigmas ultrapassados. $\bigcirc$ conservadorismo doméstico não persiste num mundo globalizado. Atenta contra a própria sociedade brasileira.

Dessa forma, o presente trabalho pretende contribuir com o estudo e aplicação do incidente de resolução de demandas repetitivas, aclamado instituto prescrito pelo novo código, que transporta grande expectativa como instrumento colaborativo dos notórios problemas hodiernos do Poder Judiciário.

\section{REFERÊNCIAS}

ANDREUCCI, Álvaro Gonçalves Antunes. Uma revalorização do direito a partir de Paul Ricoeur: o justo, a responsabilidade e a sustentabilidade. Justiça e [o Paradigma da] Eficiência: celeridade processual e efetividade dos direitos [recurso eletrônico]. Vladmir Oliveira da Silveira, Orides Mezzaroba, Mônica Bonetti Couto Samyra Haydêe Del Farra Nasponili Sanches [coord.] - Curitiba: Clássica, 2013.

AQUINO, Fabiano Gosi de. O sistema de precedentes judiciais no novo cpc: o incidente de resolução de demandas repetitivas como técnica de padronização decisória. Processo, jurisdição e efetividade da justiça III [Recurso eletrônico on-line] organização CONPEDI/UnB/UCB/IDP/UDF; Coordenadores: Antonio Celso Baeta Minhoto, Celso Hiroshi locohama, Marcelo Labanca Corrêa De Araújo - Florianópolis: CONPEDI, 2016.

BAHIA, Alexandre Gustavo Melo Franco. Código de Processo Civil Anotado. Coordenação: José Rogério Cruz e Tucci, Manoel Caetano Ferreira Filho, Ricardo de Carvalho Aprigliano, Rogéria Fagundes Dotti, Sandro Gilbert Martins. AASP, 2015.

BARROS, Flaviane de Magalhães. O direito ao processo em tempo devido e o modelo 
constitucional de processo. Justiça e [o Paradigma da] Eficiência: celeridade processual e efetividade dos direitos [recurso eletrônico]. Vladmir Oliveira da Silveira, Orides Mezzaroba, Mônica Bonetti Couto, Samyra Haydêe Del Farra Nasponili Sanches [coord.]-Curitiba: Clássica, 2013.

BENACCHIO, Marcelo. e SANCHES, Samyra Haydêe Dal Farra Naspolini. A efetivação dos direitos humanos sociais no espaço privado. A problemática dos direitos humanos fundamentais na América Latina e na Europa - desafios materiais e eficaciais. Org. Narciso Leandro Xavier Baez. Joaçaba: Ed UNOESC, 2012.

CATHARINA, Alexandre de Castro. A construção dialógica dos precedentes judiciais: breves reflexões sobre democratização do processo judicial. REDES-Revista Eletrônica Direito e Sociedade. Canos, vol.4, n. I, maio 2016. Disponível em: http://revistas.unilasalle.edu.br/index.php/redes/article/view/23 I 8-808 I . 16. I 0/pdf. Acesso em 20 jul. 2017.

COELHO, Saulo de Oliveira Pinto. e MELLO, Rodrigo Antonio Calixto. A sustentabilidade como um direito fundamental: a concretização da dignidade da pessoa humana e a necessidade de interdisciplinaridade do direito. Veredas do Direito, Belo Horizonte, v.8, n. 15, p. 9-24, janeiro/junho de 201 I.

DIDIER JR, Fredie. Curso de direito processual civil: o processo nos tribunais, recursos, ações de competência originária de tribunal e querela nullitatis, incidentes de competência originária do tribunal. I 4 ed. reform. V3-Salvador: Ed. JusPodivm, 2017.

FARIA, José Eduardo. O direito na economia globalizada. São Paulo: Ed Malheiros, 2002.

FIORILLO, Celso Antonio Pacheco. Curso de direito ambiental brasileiro. 14. ed. rev. , ampl. e atual. em face da Rio + 20 e do novo "Código" Florestal - São Paulo: Saraiva, 2013.

GOMES, José Renato Rocco Roland. Incidente de resolução de demandas repetitivas como forma de proteção dos interesses transindividuais. Disponível em: https://www.unimep.br/phpg/bibdig/pdfs/docs/07032016_1 52110 joserenatoroccor olandgomes_ok.pdf

GOMES, Luiz Flávio e MAZZUOLI, Valerio de Oliveira. Direito supraconstitucional: do absolutismo ao estado constitucional e humanista de direito. São Paulo: Editora Revista dos Tribunais, 2010. 
LEÃO JÚNIOR, Teófilo Marcelo de Arêa. e SACONATO, Thais Estevão. A teoria do precedentes judiciais no sistema jurídico brasileiro: segurança jurídica e acesso à justiça. Acesso à justiça II [Recurso eletrônico on-line] organização CONPEDI/UFMG/ FUMEC/Dom. Helder Câmara; coordenadores: Edna Raquel Rodrigues Santos Hogemann, José Querino Tavares Neto, Camila Silva Nicácio -Florianópolis: CONPEDI, $\quad 2015 . \quad$ Disponível e m: http://indexlaw.org/index.php/acessoajustica/article/view/368. Acesso em 19 jul. 2017.

MARINONI, Luiz Guilherme. Precedentes obrigatórios. 2 ed. São Paulo: Editora Revista dos Tribunais, 20I I.

MEDEIROS NETO, Elias Marques de. E MACHADO, Pedro Antônio de Oliveira. Princípio da cooperação no processo civil. Revista Thesis Juris - RTJ, São Paulo, v. 5, n. I, p. |63-191, Jan.-Abr. 2016.

SILVA, Denis Cortiz da. O mandado de injunção como ferramenta de promoção da cidadania. Colóquio de pesquisa das universidades paulistas. Coordenação: Vladmir Oliveira da Silveira, Samyra Haydêe Del Farra Nasponili Sanches, Mônica Bonetti Couto. São Paulo: Editora Clássica, 2016.

SIMÃO, Lucas Pinto. O incidente de resolução de demandas repetitivas ("IRDR"), 2015. Disponível em: http://www.pucsp.br/tutelacoletiva/download/incidente-deresolucao.pdf

TEMER, Sofia. Incidente de Resolução de Demanda Repetitivas. Salvador, Ed. Juspodivm, 2016.

Recebido em: 04/12/2017

Aprovado em: 17/01/2018 